Original Research

\title{
Rheological study of mudflows at Lianyungang in China
}

\author{
Jingyu $\mathrm{Xu}^{*}$, Aode Huhe \\ Key Laboratory for Mechanics in Fluid Solid Coupling Systems, Institute of Mechanics, Chinese Academy of Sciences, Beijing 100190, China
}

\section{A R T I C L E I N F O}

\section{Article history:}

Received 22 November 2013

Received in revised form

13 June 2014

Accepted 29 June 2014

Available online 1 August 2015

Keywords:

Rheology

Mudflow

Herschel-Bulkley model

Oscillatory viscoelastic properties

\begin{abstract}
A B S T R A C T
An experimental study of the rheological properties of mudflows at Lianyungang in China was carried out by the RS6000 rheometer, including steady and dynamic measurements. Five samples with the range of mud volume concentration from 0.058 to 0.179 were investigated. Based on the experimental data, a Dual-Herschel-Bulkley model was developed to analyze the flow curve and interpolate the static and dynamic yield stresses. The results show that in the steady measurement, the consolidation time and the system temperature show some effects on the rheogram and the yield stress for the sample with low sediment volume concentration, and the effects are strengthened gradually with the sediment volume concentration increasing. Under a shear stress sweep, two linear visco-elastic regions, showing the viscous and the elastic behaviors respectively, were discovered. Complex viscosity, elastic modulus and loss modulus in the elastic region are several orders of magnitude larger than those in the viscous region. Furthermore, the analysis of experimental data show that both steady and dynamic rheological properties can be expressed as appropriate exponential functions of the sediment volume concentration.

(c) 2015 International Research and Training Centre on Erosion and Sedimentation/the World Association for Sedimentation and Erosion Research. Published by Elsevier B.V. All rights reserved.
\end{abstract}

\section{Introduction}

Natural mud is a complex mixture of saline water, cohesive sediment, organic matter and a certain amounts of sand and silt. Dilute mud suspensions can demonstrate nearly the complex behavior rheology, such as yield stress, shear-thinning, thixotropy and viscoelastic. Knowledge of these properties is important to assess the sensitivity to fluidization and erodibility, the damping of turbulence and the prediction of density currents and fluid mudflow. The rheology of sediment and water mixtures was discussed in detail by Berlamont et al. (1993) for the marine sediment transport and by Coussot $(1997,2007)$ for the mudflow, respectively. Overall, at low sediment concentrations, the mixtures usually exhibit Newtonian fluid behavior, while at high sediment concentrations the mixtures become non-Newtonian shear-thinning or viscoelastic behaviors. Furthermore, the rheological behaviors of the mixtures are also affected strongly by the physicchemical factors (flocculation).

Rheological experiments of natural mud usually include the steady and dynamic (oscillatory) measurements. In the steady measurement of mudflow, the value of the yield stress plays a central role in the interpretation and correlation of experimental

\footnotetext{
* Corresponding author. Tel.: +8610 8254 4179; fax: +861062561284.

E-mail address: xujingyu@imech.ac.cn (J. Xu).
}

results on the mudflow. The definition of yield stress is the critical stress below which the shear rate is exactly zero. In most cases, stress-strain data are extrapolated to zero-shear rate, and the intercept on the ordinate is taken to be the yield stress. Although there is a debate in the literature on the existence of a "true" yield stress, in the present study the existence of the yield stress is assumed for natural mud. In practice, it is difficult to ascribe a value to the yield stress in that both the different rheological model selected and the flow curve segmented for extrapolation lead to a wide distribution in the published data of yield stress (James et al., 1987; Julien \& Lan, 1991; Chhabra, 2006). Therefore, the yield stress obtained by different models should not be directly compared with each other and the extrapolation beyond the range of experimental conditions must be treated with caution.

In the last half-century, a number of rheological models have been used to study the mixtures of sediment and water. These models, which describe the sediment response to fluid loading, can generally be grouped into three main categories, namely liner model (Newtonian and Bigham fluids), power function model (Power-law and Herschel-Bulkley fluids) and viscoelastic model (Kelvin-Voigt fluid). The results show that both apparent viscosity and yield stress, which are obtained by these models, are largely dependent on the shear rate and increases exponentially with the sediment volume concentration increasing (O’Brien \& Julien, 1988; Huhe et al., 1994). 
Unlike the steady measurement, until now few experimental data has been published on the oscillatory measurement of natural mud (Jiang \& Metha, 1995; Kessel \& Blom, 1998; Babatope et al., 2008; Huang \& Huhe, 2009), although the test provides information on the elastic properties of the mud, which is of importance to study the wave forcing in shallow waters (Williams \& Williams, 1989). Thus, the present study focuses on the rheological behaviors of natural mud and contributes a valuable data set of the steady and dynamic rheology for the natural mud at Lianyungang.

\section{Experimental methods}

In this study, natural mud samples were taken from Lianyungang in China. They were packaged in a sealed container and shipped to the laboratory. Sediment grains are characterized by an average density of $2713 \mathrm{~kg} / \mathrm{m}^{3}$ and a median grain diameter of $6.2 \mu \mathrm{m}$ (D50). Size distribution of the sediment grains measured by two different methods is shown in Fig. 1.

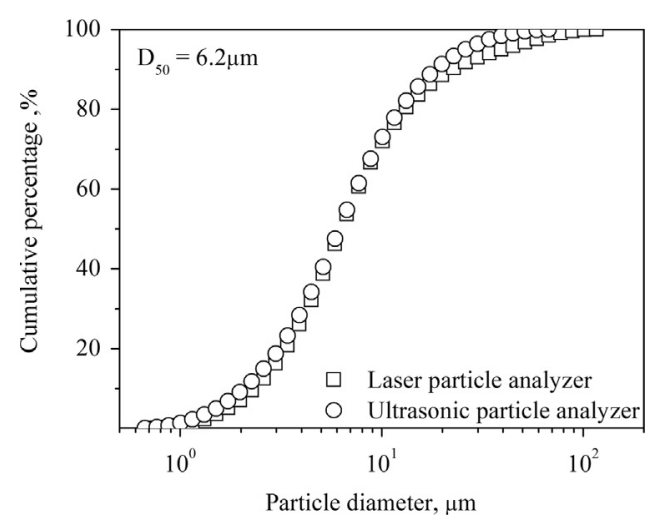

Fig. 1. Sediment size distribution measured by two different methods.

Table 1

Several basic properties of the mudflow samples.

\begin{tabular}{lllll}
\hline Sample no. & $\begin{array}{l}\text { Mud volume } \\
\text { concentration, } \\
C_{V}\end{array}$ & $\begin{array}{l}\text { Mud den- } \\
\text { sity, } \\
\rho_{c}\left(\mathrm{~kg} / \mathrm{m}^{3}\right)\end{array}$ & $\begin{array}{l}\text { Mud mass con- } \\
\text { centration, } \\
S\left(\mathrm{~kg} / \mathrm{m}^{3}\right)\end{array}$ & $\begin{array}{l}\text { Sediment } \\
\text { grains den- } \\
\text { sity, } \\
\rho_{s}\left(\mathrm{~kg} / \mathrm{m}^{3}\right)\end{array}$ \\
\hline Sample 1 & 0.058 & 1098 & 157 & 2713 \\
Sample 2 & 0.086 & 1146 & 233 & \\
Sample 3 & 0.118 & 1200 & 320 & \\
Sample 4 & 0.152 & 1256 & 412 & \\
Sample 5 & 0.179 & 1305 & 486 & \\
\hline
\end{tabular}

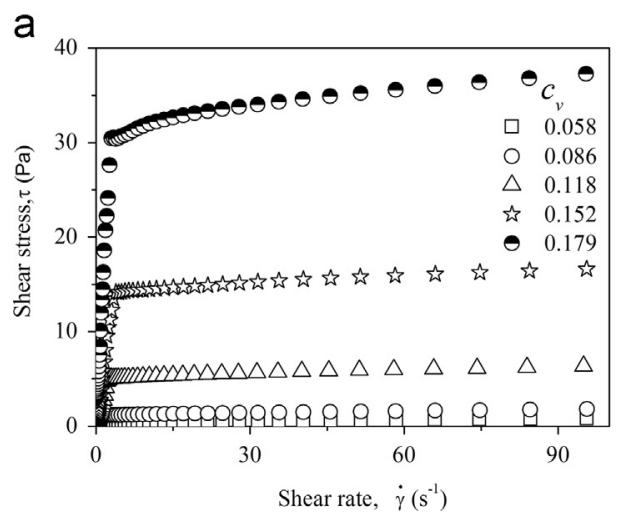

To get the desired sediment volume concentration, the natural mud samples were diluted by using the different amounts of salty water with $15 \%$ o salinity. Five mud samples with different sediment volume concentrations were studied. Several basic properties of the mudflow samples are summarized in Table 1. In the table, the mud volume concentration is equal to the ratio of the mud mass concentration to the sediment grains density $\left(s / \rho_{s}\right)$ (Whitehouse et al., 2000). During the tests, the samples were prepared in batches of $300 \mathrm{ml}$ and pre-heated to a fixed test temperature, and then the homogenization was achieved by using the three-blade stirrer at a fixed low speed. After homogenization, the rheological characterization of the samples was measured by exploiting the performance of the rheometer (Haake RheoStress 6000, Germany).

Rheological measurements were carried out on the RS6000 rheometer with a coaxial cylinder sensor system (Z38 DIN, gap width $=2.5 \mathrm{~mm}$ and sample volume of $30.8 \mathrm{~cm}^{3}$ ). In the rheometer, a temperature control system for cone and plate measuring geometries and two units with different coaxial cylinder diameters is available. Liquid temperature-controlled units can make the sensor system reach to a fixed temperature and maintain this temperature throughout the experiment. After two minutes from positioning the sample on the sensor system, the corresponding measurement was started. Three replicates of each test were performed and repeatability was good. Furthermore, this rheometer has a range of shear rates from $10^{-3} \mathrm{~s}^{-1}$ to $1000 \mathrm{~s}^{-1}$ and a range of viscosity from $0.001 \mathrm{~Pa}$ to $1000 \mathrm{~Pa}$ s. In the oscillatory measurement, an amplitude sweep at a fixed frequency of $1 \mathrm{~Hz}$ was performed prior to the following measurement of oscillatory frequency in order to ensure the selected stress keeping in the linear visco-elastic region. Experimental data were obtained by recording the complex viscosity $(\eta *)$, the elastic modulus $\left(G^{\prime}\right)$ and the loss modulus $\left(G^{\prime \prime}\right)$. Frequency ranged was from $0.01 \mathrm{rad} / \mathrm{s}$ to $100 \mathrm{rad} / \mathrm{s}$. Furthermore, a vane-type rotor (FL22) was also used to measure the yield stress of the samples according to the suggestion by Schramm (2000).

\section{Results and discussion}

\subsection{Steady mudflow}

The flow behaviors of mud at Lianyungang are investigated over a wide range of shear rates from $0.001 \mathrm{~s}^{-1}$ to $100 \mathrm{~s}^{-1}$. Fig. $2 \mathrm{a}$ shows the variation of the flow curve with the shear rates. At low shear rates, the shear stress increases quickly with the shear rate and passes through a turning point and thereafter goes up slightly. Overall, it is observed that the shear stress of the sample increases with the volume concentration increasing. Due to the fact that the internal frictional forces become greater with the sediment

$\mathrm{b}$

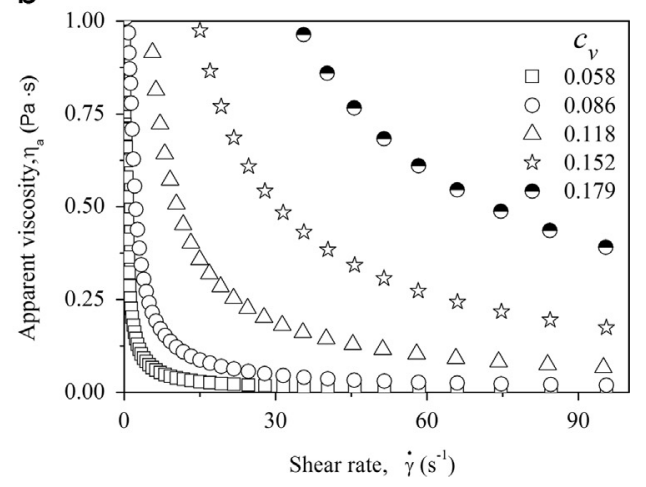

Fig. 2. Rheograms of the samples with different volume concentrations at $20^{\circ} \mathrm{C}$. 
quantity increasing, the shear stress has to be increased at a fixed shear rate (Macial, 2009). Furthermore, the mud sample shows a strong shear-shinning rheological behavior, as shown in Fig. 2b.

To predict the flow characteristics of mud, one of the best methods is to exploit a theoretical model to reveal the experimental data and obtain the yield stress. The simplest theoretical model for yield stress fluid is the Bingham model, which exhibits a linear stress-strain relationship at shear stress in excess of the yield stress. In most cases, fitting the experimental data with satisfactory accuracy is not good over the low range of shear rates by this model (Julien \& Lan, 1991; Kessel \& Blom, 1998; Toorman, 1994; Coussot et al., 1996; Maciel et al., 2009). Kessel and Blom (1998) investigated the applicability of rheological models for a natural mud and an artificial mud. Their results show that the Bingham model is only suitable for describing the measurements at shear rate in excess of $20 \mathrm{~s}^{-1}$. To overcome this problem, Huang and Huhe (2009) developed the Dual-Bingham model to predict the flow curve over the entire range of shear rates from $0.001 \mathrm{~s}^{-1}$ to $200 \mathrm{~s}^{-1}$. However, it can be found in Fig. 3 that over the range of low shear rates, the material exhibits that the stress-strain relationship is not linear and yet shows a convexity to the shear stress. This behavior is referred to as yield-pseudo-plastic. The HerschelBulkley model is proposed to fit the experimental data with this behavior (Govier \& Aziz, 1982; Mitsoulis, 2007; Maciel et al., 2009). Therefore, the Dual-Herschel-Bulkley model is developed to study the rheological characteristics of mudflow at Lianyungang.

Similar to the Dual-Bingham model, the Dual-Herschel-Bulkley model can be described by six parameters base on two different regions of the shear rates:

when $\dot{\gamma}>\dot{\gamma}_{c}$, the region is defined as the region (1):

$\tau=\tau_{01}+\eta_{01}(\dot{\gamma})^{n_{1}}$

when $\dot{\gamma} \leq \dot{\gamma}_{c}$, the region is defined as the region (2)

$\tau=\tau_{02}+\eta_{o 2}(\dot{\gamma})^{n_{2}}$

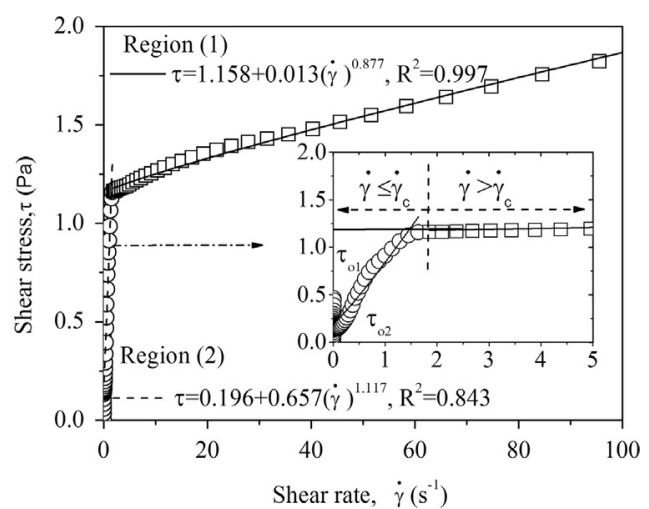

Fig. 3. A comparison of experimental data with the flow curves predicted by DualHerschel-Bulkley model for the sample 2 in a rectangular coordinate system. here, $\tau_{o}$ is the yield stress in Pa. $\eta_{o}$ and $n$ are the fluid consistency coefficient in Pa $\mathrm{s}^{n}$ (defined as the apparent viscosity of HerschelBulkley model) and the flow behavior index, respectively. The subscript 1 and 2 refer to the region (1) and region (2), respectively. $\dot{\gamma}_{c}$ is the critical shear rate and can be solved numerically by the following equation:

$\frac{\eta_{o 2}\left(\dot{\gamma}_{c}\right)^{n_{2}}-\eta_{o 1}\left(\dot{\gamma}_{c}\right)^{n_{1}}}{\tau_{o 1}-\tau_{o 2}}-1=0$

here, $\tau_{o 1}, \tau_{o 2}, \eta_{o 1}, \eta_{o 2}, n_{1}$ and $n_{2}$ are assumed as known quantities. Therefore, an iteration procedure is needed to obtain the critical shear rate. When $n_{1}=n_{2}=1$, Eq. (3) can be simplified as a first guess for this iteration procedure.

Six parameters of the Dual-Herschel-Bulkley model simulated for five samples are listed in Table 2. Fig. 3 gives a comparison of experimental data with the flow curve predicted for the sample 2 in a rectangular coordinate system. It can be observed that the shear stresses predicted by the model are good over the entire range of shear rates, especially for the high shear rates (i.e. in the region (1), $R^{2}>0.99$ ). In Fig. 3, two yield stresses obtained from the model can be interpreted as the upper limit of solid-like behavior and the lower limit of liquid-like behavior, respectively, representing the static yield stress and the dynamic yield stress (Uhlherr et al., 2005).

In hyper-concentrated flows, it has been generally accepted that the yield stress $\left(\tau_{o}\right)$ and the fluid consistency coefficient $\left(\eta_{o}\right)$ increase exponentially with the sediment volume concentration $\left(C_{V}\right)$ as:

$\tau_{01}=a_{11} \cdot e^{b_{11} \cdot c_{V}}, \dot{\gamma}>\dot{\gamma}_{c}$

$\tau_{02}=a_{12} \cdot e^{b_{12} \cdot C_{V}}, \dot{\gamma} \leq \dot{\gamma}_{c}$

$\eta_{o 1}=a_{21} \cdot e^{b_{21} \cdot c_{V}}, \dot{\gamma}>\dot{\gamma}_{c}$

$\eta_{o 2}=a_{22} \cdot e^{b_{22} \cdot c_{V}}, \dot{\gamma} \leq \dot{\gamma}_{c}$

here, the values of the eight empirical coefficients $a_{11}, a_{12}, a_{21}, a_{22}$, $b_{11}, b_{12}, b_{21}$ and $b_{22}$, obtained by the regression analysis for each mudflow sample, according to the regions (1) and (2) respectively,

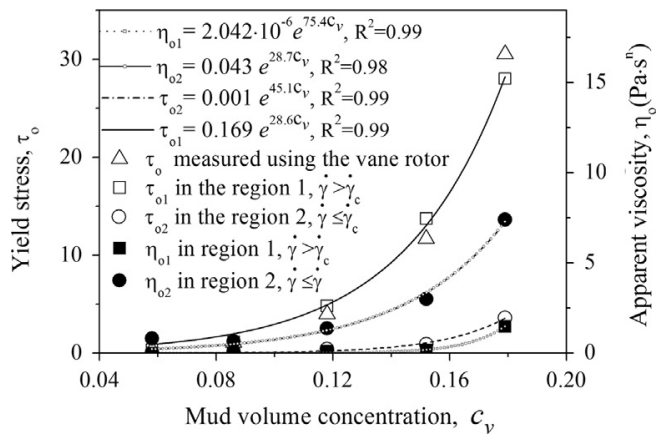

Fig. 4. Yield stress and apparent viscosity extrapolated by the Dual-HerschelBulkley model as a function of mud volume concentration at $20^{\circ} \mathrm{C}$.

Table 2

Parameters extrapolated by the Dual-Herschel-Bulkley model for mudflow samples.

\begin{tabular}{|c|c|c|c|c|c|c|c|c|}
\hline \multirow[t]{2}{*}{ Sample no. } & \multicolumn{2}{|l|}{$\tau_{o}(\mathrm{~Pa})$} & \multicolumn{2}{|l|}{$\eta_{o}\left(\mathrm{~Pa} \mathrm{~s}^{n}\right)$} & \multicolumn{2}{|l|}{$n$} & \multicolumn{2}{|l|}{$R^{2}$} \\
\hline & $\begin{array}{l}\text { Region (1) } \\
\boldsymbol{\tau}_{\boldsymbol{o 1}}\end{array}$ & $\begin{array}{l}\text { Region (2) } \\
\boldsymbol{\tau}_{\boldsymbol{o} 2}\end{array}$ & $\begin{array}{l}\text { Region (1) } \\
\eta_{\boldsymbol{o 1}}\end{array}$ & $\begin{array}{l}\text { Region (2) } \\
\boldsymbol{\eta}_{\boldsymbol{o} 2}\end{array}$ & $\begin{array}{l}\text { Region (1) } \\
\boldsymbol{n}_{\mathbf{1}}\end{array}$ & $\begin{array}{l}\text { Region (2) } \\
\boldsymbol{n}_{\mathbf{2}}\end{array}$ & $\begin{array}{l}\text { Region (1) } \\
\boldsymbol{R}_{\mathbf{1}}^{\mathbf{2}}\end{array}$ & $\begin{array}{l}\text { Region (2) } \\
\boldsymbol{R}_{\mathbf{2}}^{\mathbf{2}}\end{array}$ \\
\hline Sample 1 & 0.358 & 0.098 & 0.001 & 0.816 & 1.439 & 1.757 & 0.986 & 0.521 \\
\hline Sample 2 & 1.158 & 0.196 & 0.013 & 0.657 & 0.877 & 1.117 & 0.997 & 0.843 \\
\hline Sample 3 & 4.835 & 0.429 & 0.102 & 1.379 & 0.598 & 1.573 & 0.998 & 0.971 \\
\hline Sample 4 & 13.736 & 0.931 & 0.178 & 3.009 & 0.616 & 1.234 & 0.999 & 0.968 \\
\hline Sample 5 & 28.029 & 3.604 & 1.483 & 7.407 & 0.405 & 1.264 & 0.998 & 0.967 \\
\hline
\end{tabular}


are presented in Fig. 4. A good agreement can be observed between the experimental data and the predicted results.

In this work, a vane-type rotor is also used to measure the traditional value of static yield stress for the sample at a fixed shear rate (Schramm, 2000). The shear stress on the flow curve corresponding to a shear rate of about $0.01 \mathrm{~s}^{-1}$ is very close to the real yield stress (Mas \& Magnin, 1994; Maciel et al., 2009). Consequently, the yield stress is measured around this point by using the vane-type rotor. The results are shown in Fig. 4 by using the triangular symbol. It is observed that the measured yield stresses near to those extrapolated in the region (1) with the higher value of the dynamic yield stress. These findings further prove the validity of the model.

Consolidation process of the sediment and water materials could influence the microstructure of mud sample. After the materials are mixed, the microstructure in mud sample has already been changed. Thus, certain consolidation time is needed for the mud to restore its microstructure (Berlamont et al., 1993; Whitehouse et al., 2000). Fig. 5 shows the effects of the consolidation time on the flow curve measured. Three consolidation times, 0,30 and $60 \mathrm{~min}$, are examined by using the samples 1,2 , 4 and 5, respectively. Table 3 gives the static and dynamic yield stresses extrapolated by the Dual Herschel-Bulkley model corresponding to Fig. 5. Obviously, the consolidation time of the sample put in the coaxial cylinder sensor system shows some effects on the rheogram and the yield stress. These effects are strengthened gradually with the sediment volume concentration increasing.

Fig. 6 depicts the variation of flow curves as a function of temperature for samples 1 and 3, respectively, in a range from $5{ }^{\circ} \mathrm{C}$ to $50^{\circ} \mathrm{C}$. As can be seen, the effects of temperature on the flow curve become larger in the high shear rates (region 1) than those in the low shear rates (regions 2 ). With the sediment volume concentration increasing, this discrepancy caused by the system temperature becomes larger. The results are consistent with the findings of Maciel et al. (2009). Table 4 gives the static and dynamic yield stresses extrapolated by the Dual-Herschel-Bulkley model corresponding to Fig. 6. It can be found that an increase of the system temperature causes a slight reduction in the static yield stress of the region (2), $\tau_{o 2}$. On the contrary, the dynamic yield stress in the region (1) shows a certain degree of increase with the temperature.

\subsection{Oscillatory mudflow}

In the oscillatory measurement of mudflow, a shear stress sweep at a fixed frequency is performed prior to the oscillatory frequency in order that the selected stress is in the linear viscoelastic region. Fig. 7 shows the variations of the elastic modulus and the loss modulus with the shear stress at a fixed frequency $(f=1 \mathrm{~Hz})$ for the sample 2 . Here, they are displayed in linear coordinate and logarithmic coordinate systems, respectively. It can be observed that a solid-like behavior is observed at lower shear stresses $\left(G^{\prime}>G^{\prime \prime}\right)$ and a liquid-like behavior observed at higher shear stresses $\left(G^{\prime}<G^{\prime \prime}\right)$. The crossover shear stress $\left(G^{\prime}=G^{\prime \prime}\right)$ is found to be around $\tau=0.5 \mathrm{~Pa}$. Interestingly, there appears to be two approximate linear visco-elastic regions in the range of low and high shear stresses, respectively. Thus, in the following study the measurements of oscillatory frequency are carried out including two regions, which are defined as the viscous region and elastic region, respectively.

Fig. 8 plots that the variations of the complex viscosity, the elastic modulus and the loss modulus with the frequency for four samples at a fixed shear stress $(\tau=0.02 \mathrm{~Pa})$. An important point to

Table 3

The static and dynamic yield stresses extrapolated by the Dual-Herschel-Bulkley model corresponding to Fig. 6 (Pa)

\begin{tabular}{|c|c|c|c|c|c|c|}
\hline \multirow[t]{2}{*}{ Sample no. } & \multicolumn{2}{|c|}{ Settling time, $0 \mathrm{~min}$} & \multicolumn{2}{|c|}{ Settling time, $30 \mathrm{~min}$} & \multicolumn{2}{|c|}{ Settling time, $60 \mathrm{~min}$} \\
\hline & $\tau_{o 1}$ & $\tau_{o 2}$ & $\tau_{o 1}$ & $\tau_{o 2}$ & $\tau_{o 1}$ & $\tau_{o 2}$ \\
\hline Sample 1 & 0.359 & 0.100 & 0.364 & 0.070 & 0.430 & 0.090 \\
\hline Sample 2 & 1.158 & 0.202 & 1.223 & 0.151 & 0.586 & 0.121 \\
\hline Sample 3 & 4.876 & 0.401 & 4.575 & 0.341 & 4.855 & 0.427 \\
\hline Sample 4 & 13.727 & 0.895 & 13.038 & 0.764 & 11.150 & 0.692 \\
\hline Sample 5 & 71.866 & 19.597 & 119.623 & 30.933 & 85.892 & 50.858 \\
\hline
\end{tabular}

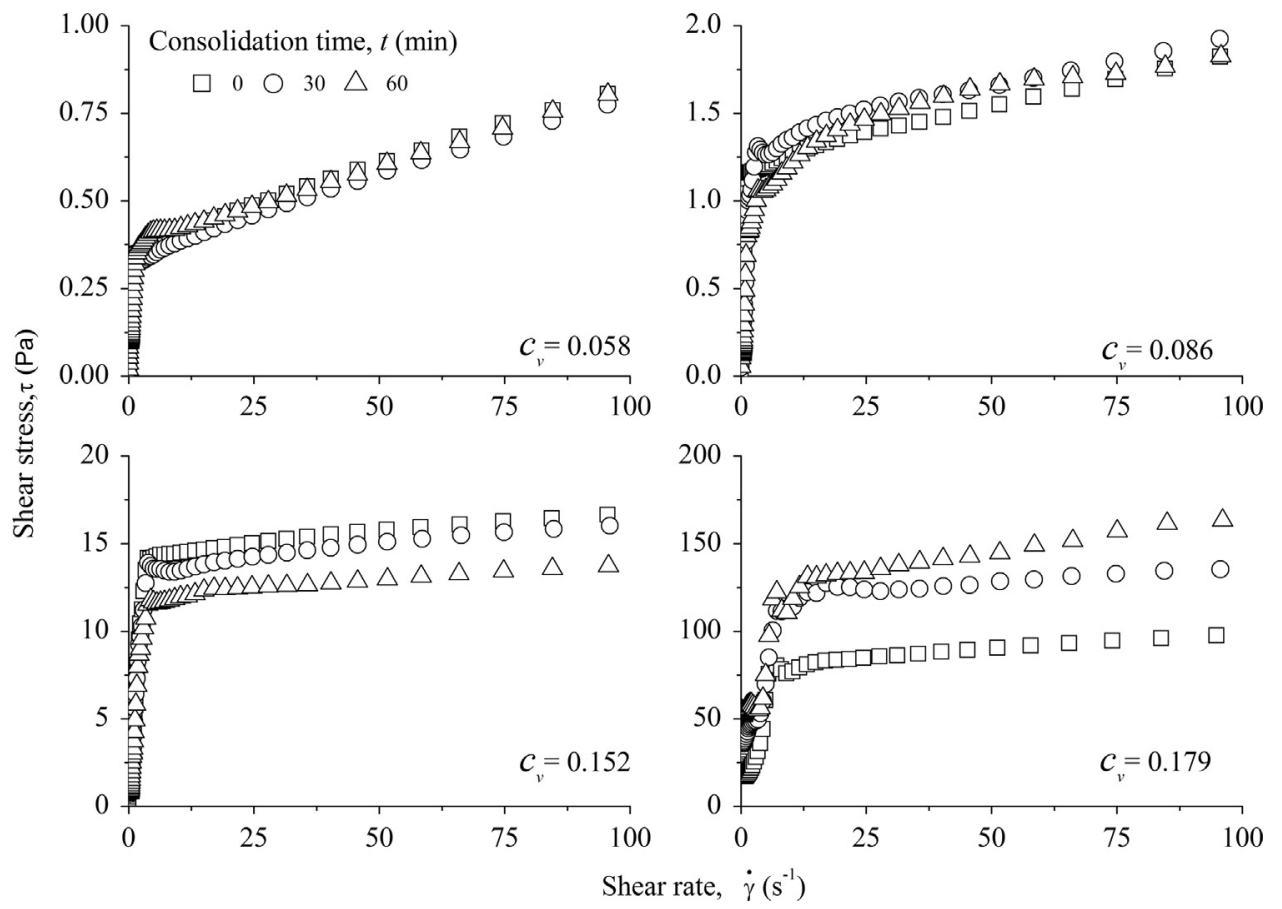

Fig. 5. Effects of consolidation time on the rheograms for four different samples at $20^{\circ} \mathrm{C}$ 
a

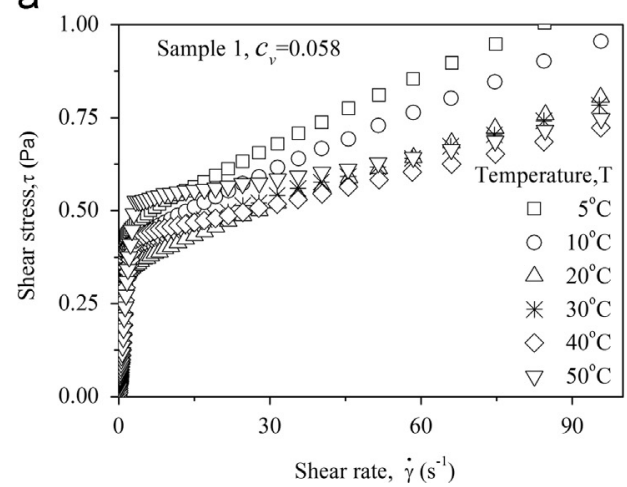

b

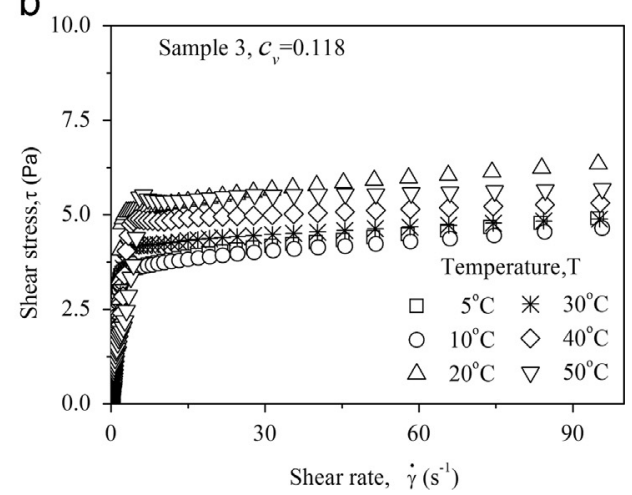

Fig. 6. Flow curves of shear rate against shear stress at different system temperatures for samples 1 and 3 , respectively.

Table 4

The static and dynamic yield stresses extrapolated by the Dual-Herschel-Bulkley model, for samples 1 and 3 , respectively corresponding to the system temperature $(\mathrm{Pa})$.

\begin{tabular}{rlllll}
\hline \multirow{2}{*}{ Temp. $\left({ }^{\circ} \mathrm{C}\right)$} & \multicolumn{2}{l}{ Sample 1} & & \multicolumn{2}{l}{ Sample 3 } \\
\cline { 2 - 3 } \cline { 5 - 6 } & $\boldsymbol{\tau}_{\boldsymbol{o 1}}$ & $\boldsymbol{\tau}_{\boldsymbol{o 2}}$ & & $\boldsymbol{\tau}_{\boldsymbol{o 1}}$ & $\boldsymbol{\tau}_{\boldsymbol{o 2}}$ \\
\hline 5 & 0.449 & 0.150 & 3.347 & 0.467 \\
10 & 0.405 & 0.098 & 3.448 & 0.416 \\
20 & 0.359 & 0.100 & 4.835 & 0.464 \\
30 & 0.440 & 0.070 & 3.996 & 0.341 \\
40 & 0.454 & 0.054 & 4.749 & 0.378 \\
50 & 0.545 & 0.050 & 5.398 & 0.390 \\
\hline
\end{tabular}

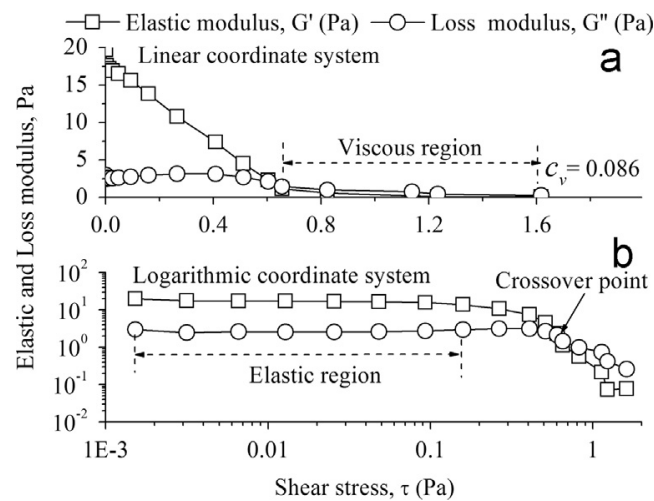

Fig. 7. Shear stress sweep at a fixed frequency $(f=1 \mathrm{~Hz})$ : variations of the elastic modulus and the loss modulus with the shear stress, displayed in linear coordinate and logarithmic coordinate systems, respectively.

note is that the elastic modulus is greater than the loss modules over the entire range of frequency, indicating that these samples are predominantly elastic. With the mud volume concentration increasing, these parameters are increased. Moreover, Fig. 8 also demonstrates that the frequency dependence of the loss modulus and the elastic modulus are rather weak over the range of low frequency and but the complex viscosity sharply decreases with the frequency increasing.

Ocean wave near shore normally has a period about $3-8$ s, i.e. an angular velocity from 0.7 to $1.5 \mathrm{rad} / \mathrm{s}$. The effects of the muddy seabed on water wave above will become weaker when wave becomes shorter or water gets deeper (Huang \& Huhe, 2009). Thus, from a practice point of view, the variations of the complex viscosity, the elastic modulus and the loss modulus with the mud volume concentration at angular velocities $\omega=0.68$ and $1.47 \mathrm{rad} / \mathrm{s}$ are given in Fig. 9, respectively. It can be seen that experimental data increase exponentially with the mud volume concentration. Thus, the least squares method is used in identifying the appropriate exponential parameters. These results are also given in Fig. 9. A very good agreement between the data and fitting curves is obtained for the complex viscosity, the elastic modulus and the loss modulus, respectively. The regression correlation coefficient ( $R^{2}$ ) is larger than 0.997 .

Furthermore, the effects of consolidation time on the oscillatory measurement for the sample with low sediment volume concentrations $\left(C_{V}=0.058\right)$ are also studied in Fig. 10. Clearly, the longer the consolidation time is, the greater the elastic modulus is. However, the loss modulus shows a low sensitivity to the variation of the consolidation time, which is similar to the measured results of steady mudflow as shown in Fig. 5. Combined with the above discussions, for the samples with low sediment volume concentrations, the consolidation time strongly changes the elastic, while plays a few effects on the viscosity.

Fig. 11 gives the results of oscillatory frequency for four samples at a fixed shear stress $(\tau=1 \mathrm{~Pa})$ in the viscous region. Unlike the results of the elastic region, the curve shows a strong dependence on the frequency. Overall, a liquid-like behavior is observed over the measured range of frequency $\left(G^{\prime}<G^{\prime \prime}\right)$. With the frequency increasing, the elastic modulus and the loss modulus maintain a continuous increase, respectively, and the complex viscosity firstly decreases and then increases. It can be seen that when the frequency reaches to about $4 \mathrm{~Hz}$, the complex viscosity shows a sudden increase. The reason may be due to the fact that the structure of the sample has been changed under the conditions of high frequency. Fig. 12 shows the variations of the complex viscosity, the elastic modulus and the loss modulus with the mud volume concentration at angular velocities $\omega=0.68$ and $1.47 \mathrm{rad} / \mathrm{s}$, respectively. The exponential relationships are also used to fit the curves. As be seen in Fig. 12, the agreement between the data with the predicted results is also acceptable.

Compared with Fig. 9, it is observed that at a fixed mud volume concentration, all three parameters in the elastic region are several orders of magnitude larger than those in the viscous region. Table 5 shows a comparison of the elastic modulus and the complex viscosity in this work with those in the literature. As be shown, the results in the present study in the elastic region are similar to those of Jiang and Mehta (1995). The values obtained in the viscous region are close to those of Huang and Huhe (2009). Huang and Huhe explained that the differe- 


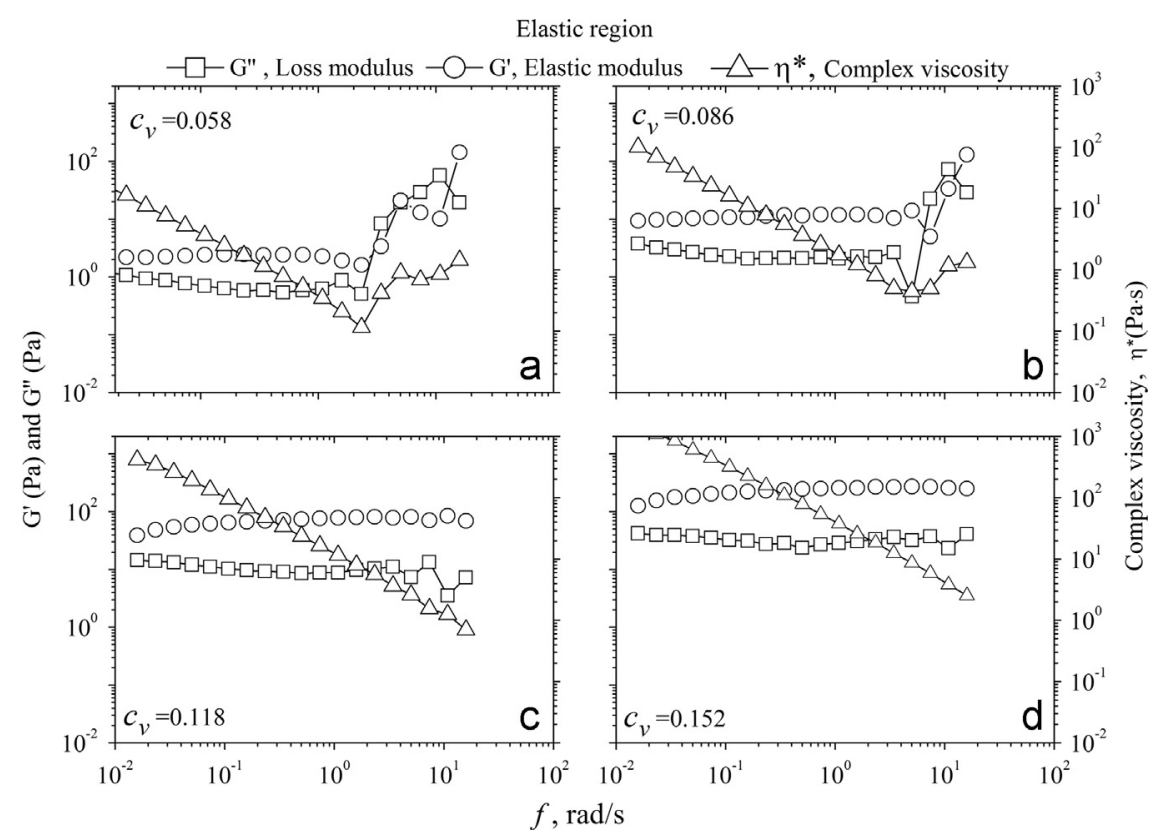

Fig. 8. Variations of the complex viscosity, the elastic modulus and the loss modulus as a function of the frequency in an elastic region.

a

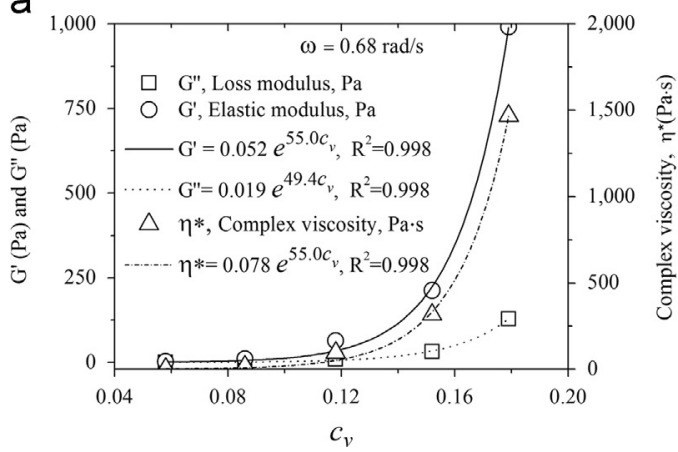

b

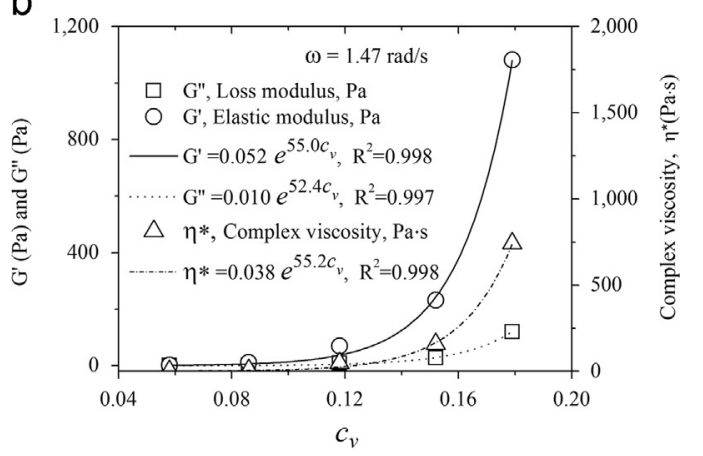

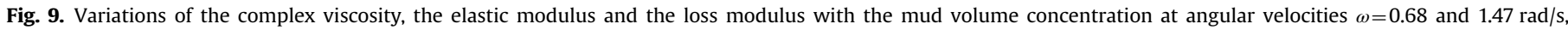
respectively, in an elastic region.

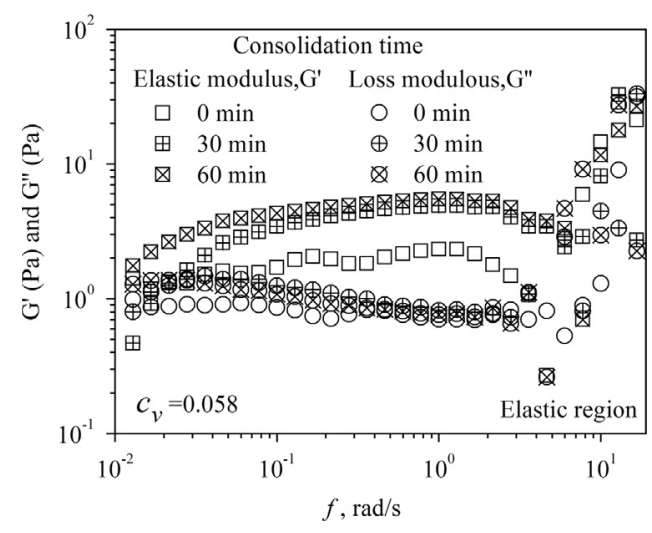

Fig. 10. Effects of consolidation time on the oscillatory mudflow for the sample 1 $\left(C_{V}=0.058\right)$

nce between their data and those in Jiang and Mehta (1995) might be due to different median gain size and organic content. However, based on the present study, the reason should be that the measurement of oscillatory frequency is carried out in the different linear visco-elastic regions, i.e. the viscous region or elastic region, respectively. Thus, the researchers should be careful to choose the shear stress for the measurement of oscillatory frequency according to the actual conditions.

\section{Conclusions}

Five samples with the range of mud volume concentration from 0.058 to 0.179 are used to study the rheological properties of steady and oscillatory mudflow by the RS6000 rheometer. Based on two different regions of the shear rates, a Dual-HerschelBulkley model is developed to describe the flow curve and obtain the yield stress. Through the analysis of the results, the following conclusions can be obtained:

(1) In the steady measurements, the consolidation time and the system temperature show some effects on the rheogram and the yield stress for the sample with low sediment volume concentration. The effects will be strengthened gradually with the sediment volume concentration increasing. 


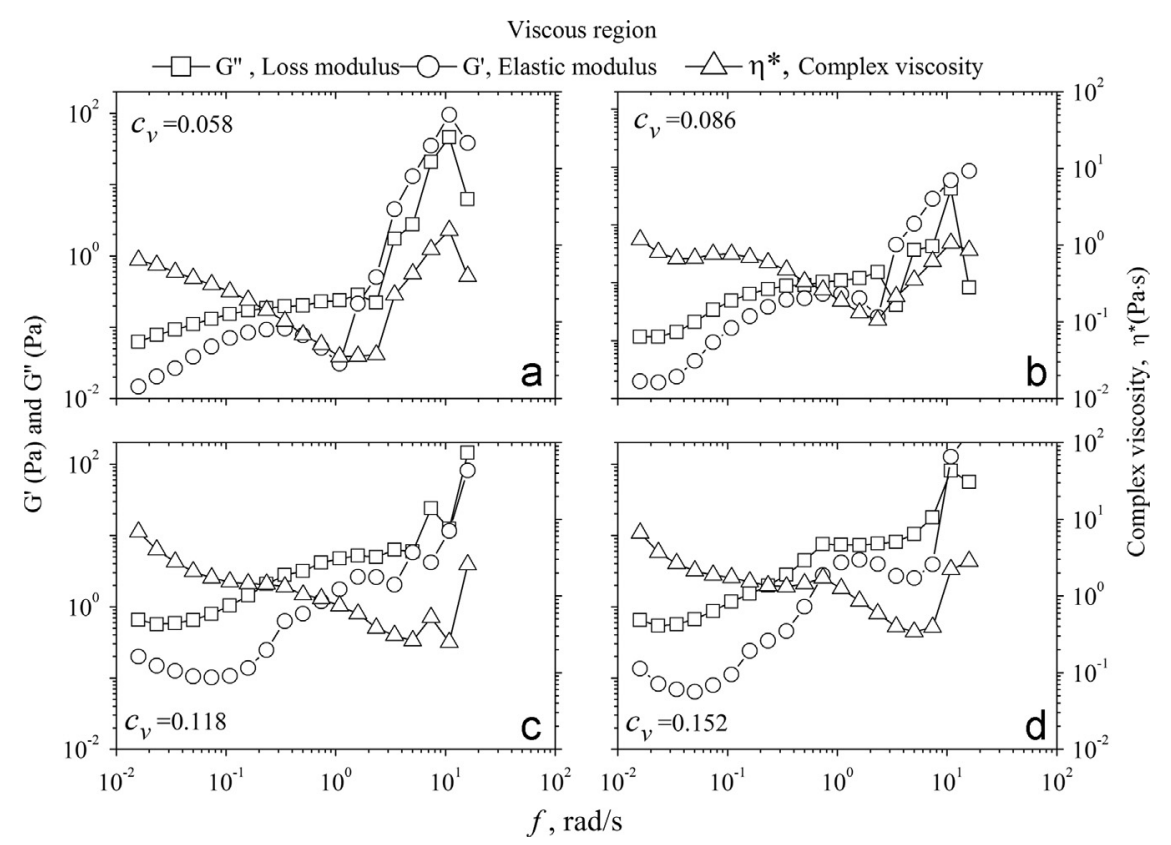

Fig. 11. Variations of the complex viscosity, the elastic modulus and the loss modulus as a function of the frequency in a viscous region.
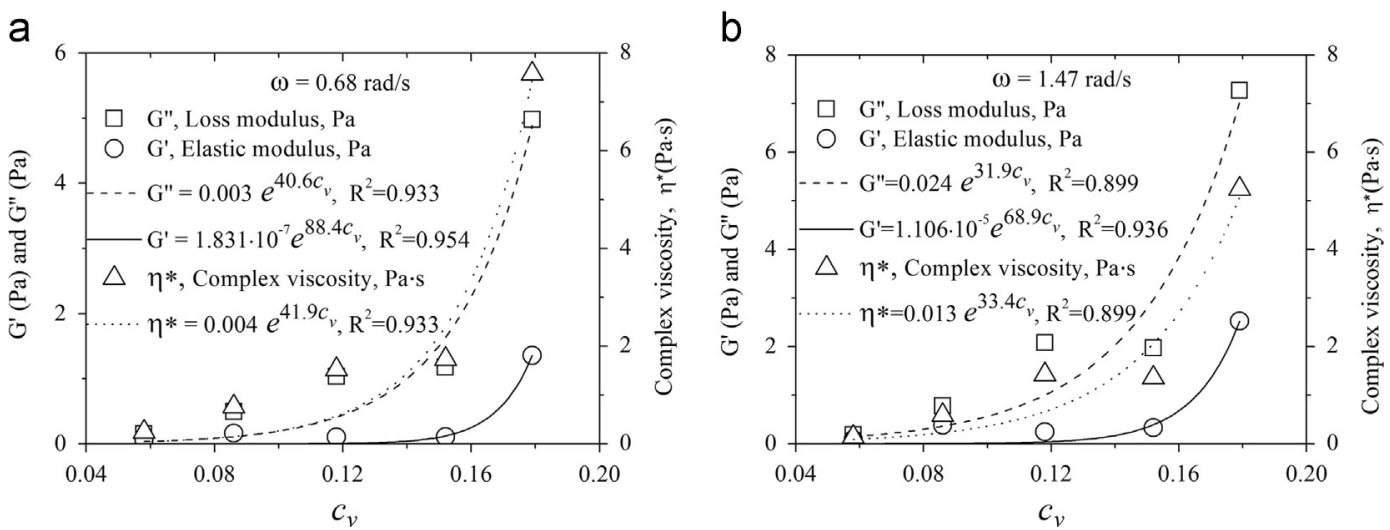

Fig. 12. Variations of the complex viscosity, the elastic modulus and the loss modulus with the mud volume concentration at angular velocities $\omega=0.68$ and 1.47 rad/s, respectively, in a viscous region.

Table 5

Comparison of the elastic modulus and viscosity in this work with those in the literature.

\begin{tabular}{lllll}
\hline Mud source & $\begin{array}{l}\text { This work } \\
\text { in elastic } \\
\text { region }\end{array}$ & $\begin{array}{l}\text { This work in } \\
\text { viscosity } \\
\text { region }\end{array}$ & $\begin{array}{l}\text { Hangzhou Bay } \\
\text { (Huang \& Huhe, } \\
\text { 2009) }\end{array}$ & $\begin{array}{l}\text { Okeechobee } \\
\text { (Jiang \& Mehta, } \\
1995)\end{array}$ \\
\hline $\mathrm{D} 50(\mu \mathrm{m})$ & 6.2 & 6.2 & 10.35 & 9 \\
$C_{V}$ & 0.118 & 0.118 & 0.12 & 0.11 \\
$G^{\prime}($ Pa) & 70 & 0.247 & 0.074 & 399 \\
$\eta^{\prime \prime} / \eta^{\prime}($ Pa s) & 48 & 1.426 & 0.129 & 71 \\
\hline
\end{tabular}

(2) In the dynamic measurement, two linear visco-elastic regions are discovered under a shear stress sweep, which are defined as the viscous region and elastic region, respectively. The complex viscosity, the elastic modulus and the loss modulus in the elastic region are several orders of magnitude larger than those in the viscous region.
(3) The steady and dynamic rheological properties of natural mudflow can be expressed as appropriate exponential functions of the sediment volume concentration.

\section{Acknowledgment}

The financial support by 300 Thousand Tons Channel Construction Project at Lianyungang is partially responsible for the conduct of this research (20100714-30HDKY008-2).

\section{References}

Babatope, B., Williams, P. R., \& Williams, D. J. A. (2008). Cohesive sediment characterization by combined sedimentation and rheological measurements. Journal of Hydraulic Engineering, 134(9), 1333-1336.

Berlamont, J., Ockenden, M., Toorman, E., \& Winterwerp, J. (1993). The characterisation of cohesive sediment properties. Coastal Engineering, 21(1-3), 105-128. 
Chhabra, R. P. (2006). Bubbles, drops, and particles in non-Newtonian fluids. Boca Raton, USA: CRC/Taylor \& Francis.

Coussot, P. (1997). Mudflow rheology and dynamics. Rotterdam, The Netherlands: A.A. Balkema.

Coussot, P. (2007). Rheophysics of pastes: a review of microscopic modelling approaches. Soft Matter, 3(5), 528-540.

Coussot, P., Proust, S., \& Ancey, C. (1996). Rheological interpretation of deposits of yield stress fluids. Journal of Non-Newtonian Fluid Mechanics, 66(1), 55-70.

Govier, G. W., \& Aziz, K. (1982). The flow of complex mixtures in pipes. New York, USA: Van Nostrand Reinhold Co.

Huang, Z., \& Huhe, A. (2009). A laboratory study of rheological properties of mudflows in Hangzhou Bay, China. International Journal of Sediment Research. 24(4), 410-424.

Huhe, A., Huang, Z. H., Zhang, Y. B., \& Jin, L. (1994). Rheology of mudflow in LianYun-Gang port. Mechanics in Engineering, 16(1), 21-24 (in Chinese).

James, A. E., Williams, D. J. A., \& Williams, P. R. (1987). Direct measurement of static yield properties of cohesive suspensions. Rheologica Acta, 26(5), 437-446.

Jiang, F., \& Mehta, A. J. (1995). Mudbanks of the southwest coast of India IV: mud viscoelastic properties. Journal of Coastal Research, 11(3), 918-926.

Julien, P. Y., \& Lan, Y. Q. (1991). Rheology of hyperconcentrations. Journal of Hydraulic Engineering, 117(3), 346-353.

Kessel, T. V., \& Blom, C. (1998). Rheology of cohesive sediments: comparison between a natural and an artificial mud. Journal of Hydraulic Research, 36(4), 591-612.
Maciel, G. F., Santos, H. K., \& Ferreira, F. O. (2009). Rheological analysis of water clay compositions in order to investigate mudflows developing in canals. Journal of the Brazilian Society of Mechanical Sciences and Engineering, 31(1), 64-74.

Mas, R., \& Magnin, A. (1994). Rheology of colloidal suspensions: case of lubrificating greases. Journal of Rheology, 38(4), 889-908.

Mitsoulis, E. (2007). Flows of viscoplastic materials: models and computations Rheology Reviews (pp. 135-178), 135-178.

O'Brien, J. S., \& Julien, P. Y. (1988). Laboratory analysis of mudflow properties. Journal of Hydraulic Engineering, 114(8), 877-887.

Schramm, G. (2000). A practical approach to rheology and rheometry. Germany: Gebrueder HAAKE GmbH.

Toorman, E. A. (1994). An analytical solution for the velocity and shear rate distribution of non-ideal Bingham fluids in concentric cylinder viscometers. Rheologica Acta, 33(3), 193-202.

Uhlherr, P. H. T., Guo, J., Tiu, C., Zhang, X. M., Zhou, J. Z. Q., \& Fang, T. N. (2005). The shear-induced solid-liquid transition in yield stress materials with chemically different structures. Journal of Non-Newtonian Fluid Mechanics, 125(2), 101-119.

Whitehouse, R., Soulsby, R., Roberts, W., \& Mitchener, H. (2000). Dynamics of estuarine muds: a manual for practical applications. USA: Thomas Telford.

Williams, P. R., \& Williams, D. J. A. (1989). Rheometry for concentrated cohesive suspensions. Journal of Coastal Research(5), S151-S164 (Spec. Issue). 